\title{
A Novel Method of Fruit Raw Material Reprocessing
}

\author{
Alexander A. Emelyanov, Konstantin A. Emelyanov \\ Oryol State Technical University, Oryol, Russia \\ E-mail: emel@ostu.ru \\ Received September 22, 2010; revised October 26, 2010; accepted November 8, 2010
}

\begin{abstract}
We introduced a method of deep resources-economy reprocessing of fruit raw material. Based on the raw material fractionation at decreased temperatures the method results in the production of bioactive food stuffs, which are dry juice and refuse and natural water. The method includes the production of directly extracted juice and pulp refuse, juice evaporation in vacuum with the production of concentrate and natural water, and air drying the concentrate and the refuse. The method is realized for garden strawberry and cucurbit pulp. The mass concentration of solid in the fractions of cucurbit pulp is defined and the specific weight of the fractions are defined. It is shown that the solid of the cucurbit pulp is uniformly allocated between the fractions and amounts $34 \%$ for the dry juice, $31 \%$ for the dry refuse, and $35 \%$ for the natural water. Food and biological values of the cucurbit pulp fractions are determined. It is determined that the cucurbit includes silicium, nickel, and chromium. Silicium is contained only in dry fractions; nickel is present everywhere; chromium is discovered only in the natural water. Food and biological values of the cucurbit pulp are defined and their allocation between the fractions is determined. Separate components concentrations of the solid considerably differ between the fractions. Thus, two thirds of pulp protein is concentrated in the dry juice and a third is concentrated in the refuse. The natural water contains up to $90 \%$ of fat and sugar, from a half to two thirds of B-group vitamins, and the bulk of the mineral substances $(\mathrm{K}, \mathrm{Na}, \mathrm{Ca}, \mathrm{Mg}, \mathrm{S}, \mathrm{Co}, \mathrm{Cu}, \mathrm{Ni}, \mathrm{Cr}$, and $\mathrm{Zn}$ ), which concentration composes from $73 \%$ for potassium up to $100 \%$ for chromium.
\end{abstract}

Keywords: Fruit Raw Material, Vacuum Evaporation, Air Drying, Bioactive Fractions, Dry Juice, Dry Pulp Refuse, Nature Fruit Water

\section{Introduction}

Different methods of fruit raw material reprocessing exist [1]. Using optimum conditions allows receiving the stuffs with high food and biological values from the fruit raw material. One of these methods is raw material drying realized for different courses of a power supply line (convection, spray-type, sublimation, etc.). Though, the classical methods of drying do not provide any ways for accumulation and utilization of the natural moisture containing in the raw material.

Currently, the vacuum sublimation drying is especially perspective reprocessing of the fruit raw material maximally preserving biological value [2]. The technology of sublimation provides product freezing down to minus $40^{\circ} \mathrm{C}$ and following heating up to plus $(40-50)^{\circ} \mathrm{C}$ in the processes of moisture evaporation. At that, the differential of general temperature of raw material is $150^{\circ} \mathrm{C}$ what requires the significant consumptions of energy and leads to the loss of thermolabile substances. Sublimated from the raw material natural moisture is accumulated in desublimate. Desublimate is removed by different methods (mechanical, thermal, ultrasonic, etc.) and is utilized.

Taking into account that the fruit raw material consists of water for $(80-90) \%$, we assume that extraction and conservation of the natural moisture, which is being removed during the process of raw material drying, will allow receiving the bioactive natural water with the unique properties. The removed moisture includes the whole spectrum of bioactive substances of the feed stock and can be used both as functional drinking water also as a source for the development of new beverages of overall, children's, dietary, and special designation. In its turn the raw material solid that persists after the natural moisture removal can be divided into soluble and insoluble one. Therefore, we can separate the fruit raw material into two more bioactive fractions. They are the dry juice, which contains soluble solid, and the dry pulp refuse including dietary fibers bulk.

At fractionation, the basic operation is the moisture 
removal from the juice of raw material. Comparing to the vacuum sublimation drying the moisture evaporation has significant advantages.

1) The evaporation does not require essential consumptions of energy at temperatures up to $50^{\circ} \mathrm{C}$. Thus, the evaporation at $45^{\circ} \mathrm{C}$ is provided by the rise of raw material temperature only on $25^{\circ} \mathrm{C}$. At sublimation with a top temperature of plus $45^{\circ} \mathrm{C}$, the temperature differential is $145^{\circ} \mathrm{C}$ and exceeds the evaporation range of change in 5.8 times. The excess increases with temperature decrease and reaches 13 -fold at $30^{\circ} \mathrm{C}$. The consumption of energy for moisture removal is directly proportional to the differential of raw material temperature. In addition, desublimate does not need to be removed at the evaporation. The energy consumption decrease on an order of value is a valid argument for the benefit of the evaporation.

2) The vacuum evaporation goes with distillate accumulation and saves up to $90 \%$ of juice moisture. The spare moisture is natural drinking water with unique properties.

3) At atmospheric pressure and temperature up to $50^{\circ} \mathrm{C}$ the final drying of concentrated juice and pulp refuse minimizes consumption of energy for the achievement of moisture level providing long-time storage at ordinary terms and room temperature.

Realized at decreased temperatures the fractionation minimizes losses of its biological value and allows receiving the food stuffs, where the content of individual components essentially exceeds their content in the feed stock.

To receive the bioactive food stuffs, we explored the fruit raw material reprocessing by fractionation into dry juice and pulp refuse and natural water.

\section{Method}

After preliminary preparation, the fruit raw material is being separated by a physical force into juice and pulp refuses [3]. The juice is being evaporated in vacuum at a residual pressure of $P=(1-10) \quad \mathrm{Pa}$ and a temperature of $t=(30-50){ }^{\circ} \mathrm{C}$ with the production of concentrate and distillate of the juice. The distillate is feed stock moisture and can be used as drinking water so as a source for preparation of functional beverages [4].

In the process of evaporation, the concentrate possesses with a high moisture content of $(40-60) \%$ and is useless for a continuous storage. The humidity of the pulp refuse is high too. To provide a possibility of continuous storage in ordinary terms at room temperature, we dried the concentrate and the refuse in air at temperature below $50^{\circ} \mathrm{C}$.

Subject to a raw material type, the dry juice takes a shape of a paste or pellets after extrusion $[5,6]$. The juices of the cherry, the grape, the hawthorn, the cucurbit, etc. have a shape of a paste. The juices of the arrowwood, the garden strawberry, the blackcurrant, the plum, etc. have a pelleted shape. Under the necessity, the pellets are powdered [7].

The block diagram of the raw material reprocessing is presented in Figure 1.

\section{Experimental}

The fractionation method is realized for garden strawberry and cucurbit pulp. After preliminary preparation, the raw material was physically pressed. At garden strawberry pressing the output made $83 \%$ for the juice and $17 \%$ for the refuse. Cucurbit pulp output made $74 \%$. The pulp was separated into the directly extracted juice $74 \%$ and the pulp refuse $26 \%$.

The directly extracted juice was separated to concentrate and distillate by the force of evaporation. The evaporation is being executed via the vacuum distiller [8], which schematic diagram is presented in Figure 2.

The vacuum distiller contains evaporator 1 , which is connected via vapor line 2 to horizontal condenser 3 . Via pipeline 4 , it is joined to vertical condenser 5 . The vertical condenser cools the condensate and is joined to hotwell 6 . The hotwell is connected via valve 7 to a backing pump 8 , which secures a vacuum of (6-10) $\mathrm{Pa}$. The evaporator has windows 9 for watching the boiling. Working bodies 10 are placed in the evaporator at drying. Electric heater 11 is mounted in the evaporator jacket.

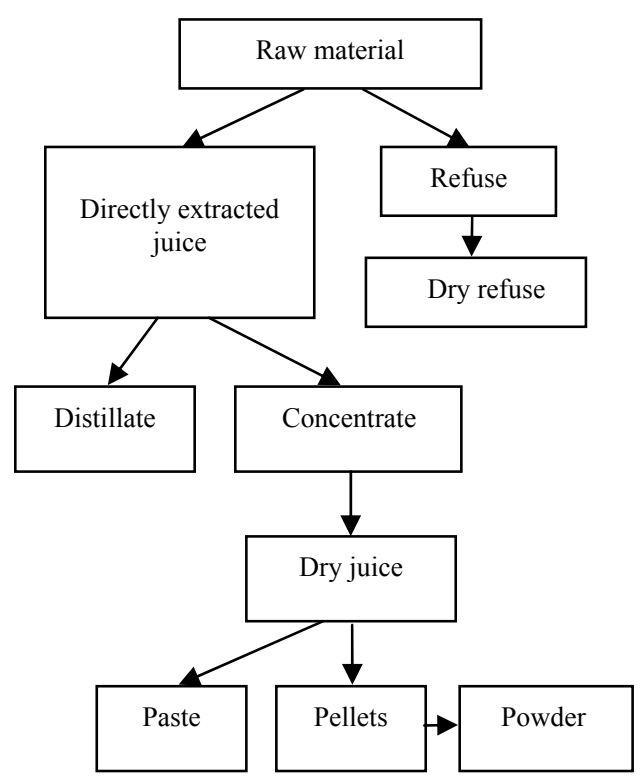

Figure 1. Block diagram of the raw material reprocessing. 


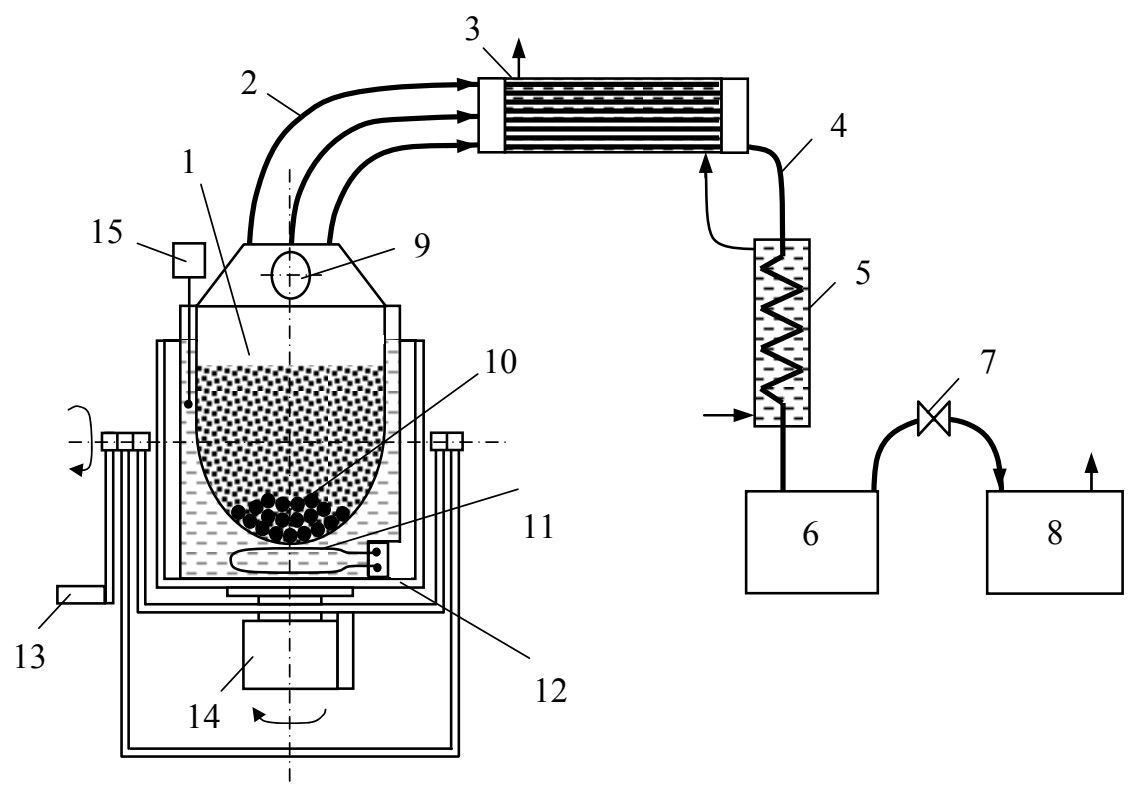

Figure 2. Schematic diagram of the facilities: (1) evaporator, (2) vapor line, $(3,5)$ condensers, (4) pipeline, (6) hotwell, (7) valve, (8) vacuum pump, (9) window, (10) working bodies, (11) tubular electric heater, (12) cell, (13) handle, (14) drive for oscillatory motion, and (15) temperature controller.

The evaporator is placed in cell 12 with two rotation axes. Handle 13 is used for changing the position of the cell's axis of symmetry. Drive 14 provides oscillatory rotation of the cell by a half-turn about the axis of symmetry and mixing the product at drying. Temperature controller 15 keeps the temperature at a predetermined level. The distiller condensers are water-cooled. The vacuum distiller work is shown in [9].

We maintained temperature in the evaporator at the level of $50^{\circ} \mathrm{C}$ by the force of power control. The time dependences of the temperature $t(\tau)$, the residual pressure, $P(\tau)$, and the evaporation curve, $V(\tau)$, for the cucurbit juice are shown in Figure 3.

It follows from the curves of $t(\tau), P(\tau)$, and $V(\tau)$ that the evaporation went at $t \approx 50{ }^{\circ} \mathrm{C}$ and $P=7 \quad \mathrm{~Pa}$ with the condensate reached the hotwell with a specific rate of $1(\mathrm{kWh})^{-1}$ reduced to the heating power.

In the evaporation process, the juice was separated to the concentrate and the natural water. The output made $27 \%$ of the concentrate and $56 \%$ of the water for the garden strawberry and $12 \%$ of the concentrate and $62 \%$ of the water for the cucurbit pulp.

The distillate was pure toothsome drinking water with a flavor of the garden strawberry or the cucurbit, respectively. We explored the hardness of cucurbit water. Its hardness is 30 times lower than running water hardness and is equal to $0.3 \mathrm{mg}$-eq./l. The advanced softness beneficially exerts to organoleptic properties and a physiological action of the natural water.

The external view of the natural cucurbit water is shown in Figure 4.

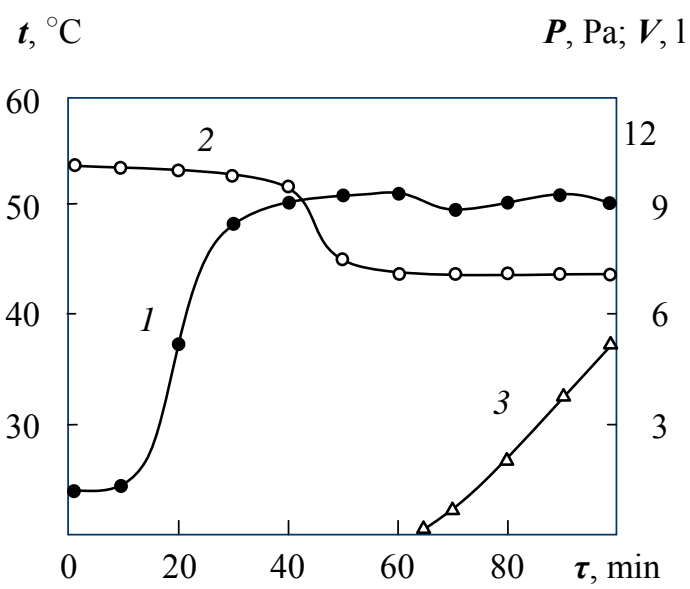

Figure 3. Time dependences of evaporation temperature (1) and residual pressure (2) and evaporation curve (3).

The moisture content of the concentrates was $42 \%$ for the garden strawberry and $46 \%$ for the cucurbit. To provide a possibility of the continuous storage, we dried the concentrates and the refuses in a convective dryer at temperatures below $50^{\circ} \mathrm{C}$ with the production of dry juices and refuses.

The dry cucurbit juice was paste-shaped and virtually was cucurbit honey. The strawberry juice was pelleted in the process of air drying.

Table 1 shows data on output and moisture of garden strawberry and cucurbit pulp fractions.

The external views of the dry cucurbit and strawberry juices are shown in Figure 5. 


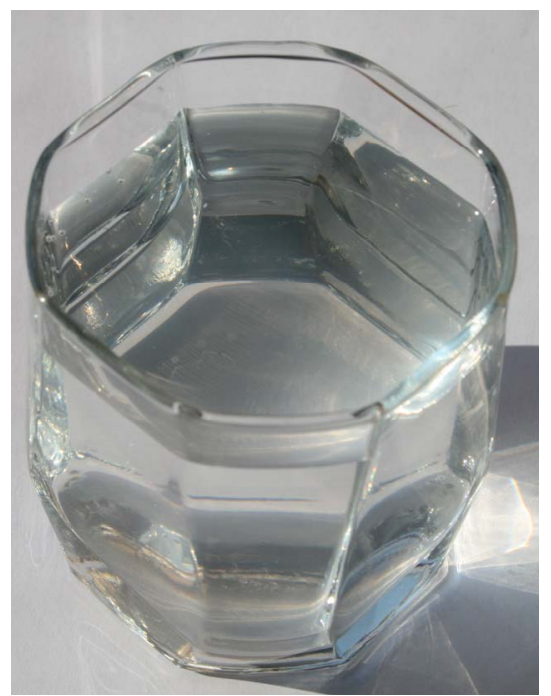

Figure 4. Cucurbit natural water.

Table 1. The output and the humidity of garden strawberry and cucurbit pulp fractions.

\begin{tabular}{cccccccc}
\hline \multirow{2}{*}{ No } & \multirow{2}{*}{ Factor } & \multicolumn{3}{c}{ Garden strawberry } & \multicolumn{3}{c}{ Cucurbit pulp } \\
\cline { 3 - 8 } & & Juice & Refuse & Water & Juice & Refuse & Water \\
\hline 1 & Output, \% & 6.8 & 3.2 & 56 & 4.8 & 3.4 & 62 \\
2 & Humidity, \% & 14 & 7 & - & 27 & 6 & - \\
\hline
\end{tabular}

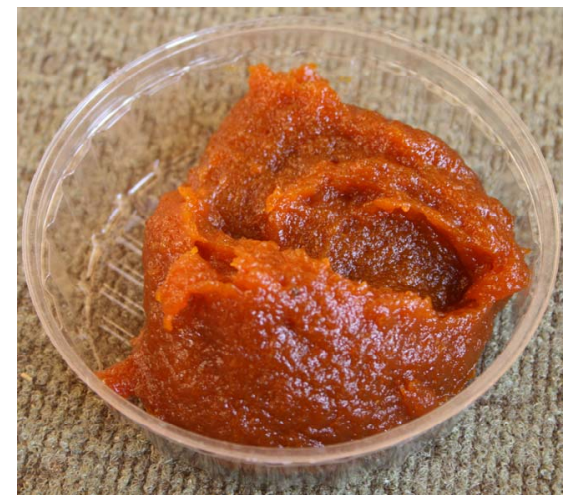

(a)

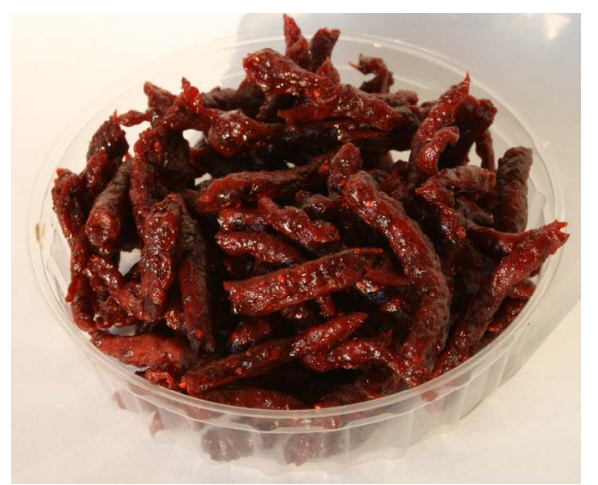

(b)

Figure 5. Dry juices of cucurbit with humidity of $27 \%$ (a) and garden strawberry with humidity of $14 \%$ (b).
The pulp refuses was powdered in the process of air drying. The moisture content of the dry refuse was $7 \%$ for the garden strawberry and $6 \%$ for the cucurbit. The external views of dry cucurbit and strawberry refuses are shown in Figure 6.

The reprocessing losses were $34 \%$ for the garden strawberry and $30 \%$ for the cucurbit pulp. They can be reckoned among the moisture losses gone with the air drying. The solid mass concentration came to $5.95 \%$ for the natural water. Taking into account the specific weight of the fractions, we determined the solid percentage $10.4 \%$ and a uniformity of its distribution between the fractions. The solid amounts $34 \%$ for the dry juice, $31 \%$ for the dry refuse, and $35 \%$ for the natural water.

To show the regularities for the distribution of the food and biological values, we explored physicochemical properties of the fractions.

\section{Physicochemical Properties}

To examine the physicochemical properties of the cucurbit pulp fractions, we used classical methods.

Table 2 shows the food value of the cucurbit pulp fractions.

It follows from Table 2 that the dry juice corresponds

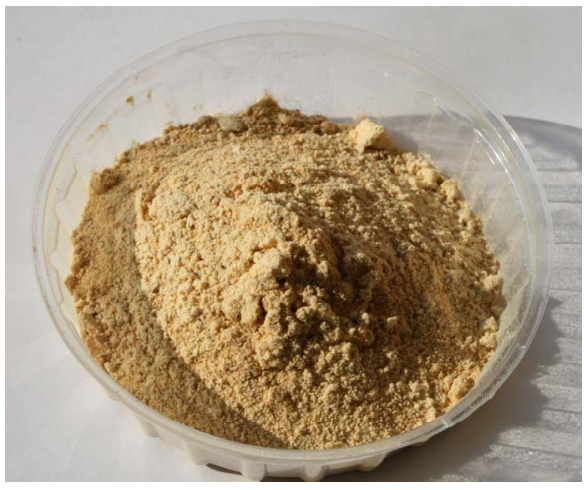

(a)

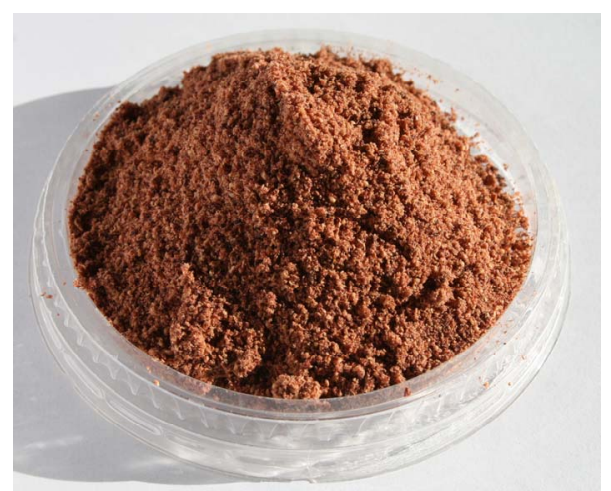

(b)

Figure. 6. Dry refuses of cucurbit pulp with humidity of $6 \%$ (a) and garden strawberry with humidity of $7 \%$ (b). 
Table 2. The food value of the cucurbit pulp fractions.

\begin{tabular}{ccccc}
\hline No & Factor & Juice & Refuse & Water \\
\hline 1 & Solid, \% & 73.0 & 94.0 & 5.95 \\
2 & Protein, \% & 25.4 & 22.2 & 0.03 \\
3 & Fat, \% & 0.18 & 0.18 & 0.1 \\
& Total sugar, \% & 5.3 & 4.6 & 5.5 \\
4 & including reducing sugar & 2.9 & 2.1 & 3.7 \\
& Dietary fibers, \% & 4.52 & 28.1 & 0.12 \\
5 & including: cellulose & 3.75 & 24.5 & - \\
& pectin & 0.77 & 3.54 & 0.12 \\
6 & Organic acids, \% & 0.23 & 0.56 & 0.03 \\
7 & Ash, \% & 0.42 & 0.52 & 0.1 \\
8 & Mineral substances, $\mathrm{mg} / 100 \mathrm{~g}$ & 287 & 312 & 119 \\
9 & Caloric content, $\mathrm{kJ} / 100 \mathrm{~g}$ & 533 & 470 & 97 \\
\hline
\end{tabular}

to the dry refuse and considerably tops the water by the protein, fat, and caloric content. The sugars are uniformly allocated between the fractions. The refuse tops the juice in 2.4 times and the natural water in 20 times by the mass concentration of the organic acids. The juice corresponds to the refuse and tops the water in 2.4 times regarding the mass concentration of the mineral substances.

The vitamins content of the cucurbit pulp fractions is presented in Table 3.

As it follows from Table 3, the content of $\beta$-carotene tops the content of B group vitamins and ascorbic acid in the dry fractions. The dry fractions exceed the feed stock regarding the vitamins content. The excess is an order of magnitude for the dry juice at that, for separate vitamins the excess multiplicity varies from 2.3 for pyridoxine up to an order of magnitude for $\beta$-carotene, thiamine, and niacin. Between the juice, the refuse, and the water, the ratio of $B$ group vitamins is equal to the ratio of ascorbic acid and composes $6 / 3 / 1$.

To satisfy the daily maintenance in vitamins, the sufficient amount of the cucurbit dry juice is $1.8 \mathrm{~g}$ for $\mathrm{A}, 180$ $\mathrm{g}$ for PP, $350 \mathrm{~g}$ for $\mathrm{B}_{1}, 400 \mathrm{~g}$ for $\mathrm{B}_{2}$, and $500 \mathrm{~g}$ for $\mathrm{B}_{6}$.

The refuse and the natural water of the cucurbit are rich with $\beta$-carotene and B group vitamins too. To satisfy the daily maintenance in vitamins, the sufficient amount is: $2.2 \mathrm{~g}$ of the refuse or $270 \mathrm{ml}$ of the natural water for $\mathrm{A}$; $325 \mathrm{~g}$ of the refuse or $850 \mathrm{ml}$ of the cucurbit water for PP; $760 \mathrm{~g}$ of the refuse or 2.11 of the natural water for $\mathrm{B}_{1}$.

Table 4 shows macro- and microelements content of the cucurbit pulp fractions.

Table 3. Vitamins content of the cucurbit pulp fractions, mg/100 g.

\begin{tabular}{ccccc}
\hline No & Factor & Juice & Refuse & Water \\
\hline 1 & $\beta$-carotene & 510 & 410 & 3.3 \\
2 & Thiamine, B1 & 0.47 & 0.25 & 0.09 \\
3 & Riboflavin, B2 & 0.24 & 0.13 & 0.03 \\
4 & Pyridoxine, B6 & 0.20 & 0.13 & 0.02 \\
5 & Niacin, PP & 5.67 & 3.66 & 1.42 \\
6 & Ascorbic acid, C & 2.99 & 1.41 & 0.35 \\
\hline
\end{tabular}

Table 4. Macro- and microelements content of the cucurbit pulp fractions, $\mathrm{mg} / 100 \mathrm{~g}$.

\begin{tabular}{ccccc}
\hline No & Factor & Juice & Refuse & Water \\
\hline 1 & Potassium, K & 150.8 & 146.3 & 53.2 \\
2 & Sodium, Na & 3.07 & 1.58 & 1.1 \\
3 & Calcium, Ca & 71.9 & 104.5 & 38.3 \\
4 & Silicium, Si & 11.2 & 17.1 & - \\
5 & Magnesium, Mg & 11.2 & 11.5 & 8.5 \\
6 & Phosphorus, P & 13.2 & 11.4 & 1.17 \\
7 & Sulfur, S & 22.1 & 14.0 & 14.1 \\
8 & Iron, Fe & 0.4 & 2.5 & 0.13 \\
9 & Cobalt, Co & 0.015 & 0.014 & 0.016 \\
10 & Manganese, Mn & - & 0.5 & - \\
11 & Copper, Cu & 1.25 & 1.13 & 1.22 \\
12 & Nickel, Ni & 0.012 & 0.011 & 0.012 \\
13 & Chromium, Cr & - & - & 0.04 \\
14 & Zinc, Zn & 1.41 & 1.23 & 1.31 \\
15 & Total sum & 287 & 312 & 119 \\
\hline
\end{tabular}

It follows from Table 4, that for the dry fractions the mass concentration of the mineral substances compounds near $300 \mathrm{mg} / 100 \mathrm{~g}$ and exceeds their concentration in the natural water in 3 times. It is established that silicium, nickel, and chromium are present in cucurbit. Silicium is contained only in the dry fractions; nickel is contained in all fractions. Chromium is exhibited only in the natural water. The high content of chromium $0.04 \mathrm{mg} / 100 \mathrm{~g}$ allows occluding its daily maintenance by $150 \mathrm{ml}$ of the cucurbit water.

The refuse has the maximal content of calcium, silicium, and iron. The excess multiplicity is 6.25 for Fe and 1.5 for $\mathrm{Ca}$ and $\mathrm{Si}$ relative to the dry juice. The refuse includes manganese as opposed to other fractions. The dry juice exceeds the refuse in 2 times regarding to sodium and in 1.6 times by the sulfur content. Cobalt and copper are uniformly allocated between the fractions; a hundred grams of any of them occludes the daily maintenance in copper completely and in cobalt for $30 \%$. The high content of copper, cobalt, and chromium determines the cucurbit pulp fractions in the capacity of the functional ingredients of the food stuffs.

\section{Distribution of Food and Biological Values between the Fractions}

Taking into account the food and biological values of the fractions and their specific weight, we calculated the food and biological values of the cucurbit pulp and established its distribution between the fractions.

The value of an individual factor $G_{i}$ is equal to its values sum of all fractions,

$$
G_{i}=\sum_{k=1}^{3} g_{i k} w_{k},
$$

where $g_{i k}$ is content of $i$-th factor in $k$-th fraction; $w_{k}$ 
is output of $k$-th fraction. We calculated the distribution of $i$-th factor between the fractions by its part $G_{i k}$ in $k$-th fraction.

$$
G_{i k}=\frac{g_{i k} w_{k}}{\sum_{k=1}^{3} g_{i k} w_{k}} 100 \%
$$

Food value of the cucurbit pulp and its distribution between the fractions are shown in Table 5.

It follows from Table 5 that the food value is irregularly allocated between the cucurbit pulp fractions. Thus, two thirds of protein is concentrated in the dry juice and one third is concentrated in the refuse. The natural water includes the bulk of fat (81\%) and sugar (90\%), three fourth of the mineral substances, two thirds of organic acids, one third of pectin, and a sixth part of vitamins. The dietary fibers bulk (77\%) is contained in the refuse. Pectin is allocated between the refuse, the water, and the juice in the ratio of $5 / 3 / 2$. The correlation of $1 / 2 / 2$ takes place for organic acids of the juice, the refuse, and the water.

The vitamins content of the cucurbit pulp and its distribution between the fractions are shown in Table 6 .

As it follows from Table 6, two thirds of $\beta$-carotene is concentrated in the dry juice and one third is concentrated in the refuse. The natural water contains from a half to two thirds of B group vitamins, the residual part is allocated between the juice and the refuse in the proportion of $(2.2-2.6) / 1$. Vitamin $\mathrm{C}$ is distributed among the refuse,

Table 5. Food value of the cucurbit pulp and its distribution between the fractions.

\begin{tabular}{cccccc}
\hline No & Factor & Pulp \% & Juice \% & $\begin{array}{c}\text { Refuse } \\
\%\end{array}$ & $\begin{array}{c}\text { Wa- } \\
\text { ter \% }\end{array}$ \\
\hline 1 & Protein & 2.0 & 61 & 38 & 1 \\
2 & Fat & 0.08 & 11 & 8 & 81 \\
3 & Total sugar, & 3.8 & 7 & 4 & 89 \\
& including: reduce sugar & 2.5 & 6 & 3 & 91 \\
4 & Dietary fibers, & 1.34 & 17 & 77 & 6 \\
4 & including: cellulose & 1.1 & 18 & 82 & - \\
5 & pectin & 0.24 & 16 & 53 & 31 \\
6 & Organic acids & 0.05 & 23 & 39 & 38 \\
7 & Ash & 0.1 & 20 & 18 & 62 \\
8 & Vitamins & 8.7 & 53 & 30 & 17 \\
\hline
\end{tabular}

Table 6. Vitamins value of the cucurbit pulp and its distribution between the fractions.

\begin{tabular}{cccccc}
\hline No & Factor & $\begin{array}{c}\text { Pulp } \\
\mathrm{mg} / 100 \mathrm{~g}\end{array}$ & $\begin{array}{c}\text { Juice } \\
\%\end{array}$ & $\begin{array}{c}\text { Refuse } \\
\%\end{array}$ & $\begin{array}{c}\text { Wa- } \\
\text { ter \% }\end{array}$ \\
\hline 1 & $\beta$-carotene & 41.4 & 60 & 35 & 5 \\
2 & Thiamine, B1 & 0.09 & 26 & 10 & 64 \\
3 & Riboflavin, B2 & 0.03 & 32 & 13 & 55 \\
4 & Pyridoxine, B6 & 0.03 & 37 & 17 & 46 \\
5 & Niacin, PP & 1.3 & 22 & 10 & 68 \\
6 & Ascorbic acid, C & 0.4 & 35 & 12 & 52 \\
\hline
\end{tabular}

the juice, and the water in the relation of $1 / 3 / 4$.

Table 7 shows macro- and microelements content of the cucurbit pulp and its distribution between the fractions.

It follows from Table 7 that the mineral substances of the cucurbit pulp (K, Na, $\mathrm{Ca}, \mathrm{Mg}, \mathrm{S}, \mathrm{Co}, \mathrm{Cu}, \mathrm{Ni}, \mathrm{Cr}$, and $\mathrm{Zn}$ ) are concentrated in the natural water and are composed from $73 \%$ for potassium to $100 \%$ for chromium. Silicium is equally allocated between the dry fractions. Manganese is only contained in the refuse. Phosphorus is distributed between the refuse, the juice, and the water in the relation of $1 / 2 / 2$. Iron is allocated between the juice, the water, and the refuse in the ratio of $1 / 4 / 5$.

\section{Conclusions}

Thus, we introduced the resource saving reprocessing method of fruit raw material. The method is based on the raw material fractionation at lowered temperatures.

The method allows separating the natural water, the dry juice and the pulp refuse from raw material at minimum loss of the biological value. The processing base is the vacuum evaporation of direct extraction juice. Unlike especially perspective sublimation drying, the vacuum evaporation has serious advantages. They are the decrease of electric energy consumption for moisture removal on an order of value and saving the fruit raw material moisture up to $90 \%$.

Garden strawberry and cucurbit pulp reprocessing with fraction separation into the dry juice, the dry refuse, and the natural water is realized. The specific weight of the fractions compounds $6.8 \%$ of the dry juice, $3.2 \%$ of the dry refuse, and $56 \%$ of the natural water for the garden strawberry and $4.8 \%$ of the dry juice, $3.4 \%$ of the dry refuse, and $62 \%$ of the natural water for the cucurbit pulp. The reprocessing losses composed $34 \%$ for the garden strawberry and $30 \%$ for the cucurbit pulp and were related

Table 7. Macro- and microelements content into the cucurbit pulp and its distribution between the fractions.

\begin{tabular}{cccccc}
\hline No & Factor & $\begin{array}{c}\text { Pulp } \\
\mathrm{mg} / 100 \mathrm{~g}\end{array}$ & $\begin{array}{c}\text { Juice } \\
\%\end{array}$ & $\begin{array}{c}\text { Refuse } \\
\%\end{array}$ & $\begin{array}{c}\text { Wa- } \\
\text { ter } \%\end{array}$ \\
\hline 1 & Potassium, K & 45 & 16 & 11 & 73 \\
2 & Sodium, Na & 0,9 & 17 & 6 & 77 \\
3 & Calcium, Ca & 31 & 11 & 12 & 77 \\
4 & Silicium, Si & 1,1 & 48 & 52 & - \\
5 & Magnesium, Mg & 6,2 & 9 & 6 & 85 \\
6 & Phosphorus, P & 1,8 & 37 & 22 & 41 \\
7 & Sulfur, S & 10,3 & 10 & 5 & 85 \\
8 & Iron, Fe & 0,19 & 10 & 47 & 43 \\
9 & Cobalt, Co & 0,01 & 7 & 4 & 89 \\
10 & Manganese, Mn & 0,02 & - & 100 & - \\
11 & Copper, Cu & 0,85 & 7 & 5 & 88 \\
12 & Nickel, Ni & 0,008 & 7 & 5 & 88 \\
13 & Chromium, Cr & 0,02 & - & - & 100 \\
14 & Zinc, Zn & 0,92 & 7 & 4 & 89 \\
15 & Total sum & 98 & - & - & - \\
\hline
\end{tabular}


to the moisture losses gone with the air drying the concentrate and the refuse. The cucurbit pulp solid is uniformly allocated between the fractions and amounts $34 \%$ for the dry juice, $31 \%$ for the dry refuse, and $35 \%$ for the natural water.

The physicochemical composition of the cucurbit pulp fractions is determined. The fractions possess high food and biological values. The high content of protein in the dry juice and the dry pulp refuse is shown. In the dry juice and the dry refuse the fat mass concentrations are equal and exceed their content in the natural water on $80 \%$. The sugar mass concentration is virtually uniform for all fractions. The refuse 6 times exceeds the dry juice regarding the dietary fibers content and in 2.4 times by the organic acids content.

The dry fractions considerably top the feed stock by the vitamins content. In the dry fractions the content of $\beta$-carotene considerably tops the content of B group vitamins and ascorbic acid. The ratio of $B$ group vitamins and ascorbic acid compounds $6 / 3 / 1$ for the dry juice, the dry refuse, and the natural water. In the dry juice, the mineral substances content of $300 \mathrm{mg} / 100 \mathrm{~g}$ corresponds to the content in the refuse and 3 times tops the content in the water. The refuse possesses the maximal content of calcium, silicium, and iron and tops the dry juice in 6.3 times by iron and in 1.5 times by calcium and silicium. The refuse contains manganese. The dry juice tops the refuse twofold for sodium content and in 1.6 times regarding the sulfur content. It is determined that the cucurbit includes silicium, nickel, and chromium. Silicium is contained only in the dry fractions; nickel is present everywhere; chromium is discovered only in the natural water. The high content of chromium, $0.04 \mathrm{mg} / 100 \mathrm{~g}$, lets to occlude the daily maintenance with $150 \mathrm{ml}$ of the cucurbit water. Cobalt and copper are uniformly allocated between the fractions; a hundred grams of any of them occludes the daily maintenance in cooper totally and in cobalt on $30 \%$. The high content of the bioactive components determines the cucurbit pulp fractions in the capacity of the functional ingredients of food stuff.

The food and biological values of the cucurbit pulp are defined and their allocation between the fractions is determined. The pulp solid is uniformly allocated between the fractions, though, the components concentrations in them considerably differ owing to discrepancies of the specific weights of the fractions.

Two thirds of pulp protein is concentrated in the dry juice; one third is concentrated in the refuse. The fat and sugar bulk (up to $90 \%$ ), three fourth of mineral substances, two thirds of organic acids, one third of pectin, and a sixth part of vitamins are concentrated in the natural water. The refuse contains $77 \%$ of dietary fibers. Pectin is allocated between the refuse, the water, and the juice in the relation of $5 / 3 / 2$. Organic acids are allocated between the juice, refuse, and water in the relation of $1 / 2 / 2$. Two thirds of $\beta$-carotene is concentrated in the dry juice; a third is concentrated in the refuse. The natural water contains from a half to two thirds of B group vitamins; the remainder is allocated between the juice and the refuse in the relation of (2.2-2.6)/1.

Ascorbic acid is distributed between the refuse, the juice, and the natural water in the relation of $1 / 3 / 4$. The bulk of the mineral substances of the pulp $(\mathrm{K}, \mathrm{Na}, \mathrm{Ca}$, $\mathrm{Mg}, \mathrm{S}, \mathrm{Co}, \mathrm{Cu}, \mathrm{Ni}, \mathrm{Cr}$, and $\mathrm{Zn}$ ) is allocated in the natural water and composes from $73 \%$ for potassium up to $100 \%$ for chromium. Silicium is allocated equally between the juice and the refuse. Manganese is contained only in the refuse. Phosphor is distributed between the refuse, the natural water, and the juice in the relation of $1 / 2 / 2$. Iron is allocated between the juice, the water, and the refuse in the relation of $1 / 4 / 5$.

\section{Acknowledgments}

This work is supported by the department of education and science of Russian Federation (No. 14.740.11.0513).

The authors would like to thank Dr. E. Kuznetzova (Oryol State Technical University) for the examination of the physicochemical properties of the cucurbit pulp fractions.

\section{References}

[1] V. A. Gerasimova, E. S. Belokurova and A. A. Vytovtov, "Tovarovedenie i ekspertiza vkusovykh tovarov," Sanct-Peterburg: Piter, Russian, 2005.

[2] B. P. Kamovnikov, L. S. Malkov and V. A. Voskoboinikov, "Vacuum Sublimate Drying of Food," Moscow: Agropromizdat, Russian, 1985.

[3] A. A. Emelyanov, "Resource Saving Processing of Fruits Raw Material at Lowered Temperatures," Food Processing Industry, No. 7, July 2009, pp. 28-29.

[4] A. A. Emel'janov and K. A. Emel'janov, "Flavored Water Production Method," RU Patent 2,351,238, April 2009.

[5] A. A. Emel'janov and K. A. Emel'janov, "Production Method of Dried Juice," RU Patent 2,375,931, December 2009.

[6] A. A. Emel'janov and K. A. Emel'janov, "Production Method of Dried Juice," RU Patent 2,370,164, October 2009 .

[7] A. A. Emel'janov and K. A. Emel'janov, "Production Method of Dried Juice," RU Patent 2,375,929, December 2009.

[8] A. A. Emel'yanov, K. A. Emel'yanov and Ya. A. Morozov, "Device for Removal of Moisture in Vacuum," RU Patent 2,276,314, May 2006.

[9] A. A. Emelyanov, V. V. Dolzhenkov and K. A. Emelyanov, "A Vacuum Distiller," Instruments and Experimental Techniques, Vol. 51, No. 5, May 2008, pp. 775- 778. 